\title{
ADHD History of the Concept: the Case of the Continuous Performance Test
}

\author{
Björn Albrecht • Henrik Uebel-von Sandersleben • \\ Katharina Wiedmann • Aribert Rothenberger
}

Published online: 22 January 2015

(C) Springer International Publishing Switzerland 2015

\begin{abstract}
The historic development of the attention deficit hyperactivity disorder (ADHD) construct is, in many cases, paralleled by research questions addressed with the continuous performance test (CPT). This task, the use of which dates back to the 1950s for the diagnosis of brain damage, requires responding to rare targets in a sequence of stimuli during prolonged assessment. In our review, we illustrate how the CPT was and still is used for the assessment of sustained attention and impulsivity as core features of ADHD. In addition to impaired performance at the neuropsychological level, the CPT also taps underlying brain activity that can be registered by neuroimaging techniques such as fMRI and EEG. The latter allows more detailed operationalization of ADHD theories, and reveals impairments at different stages of information processing. The CPT has also been applied for treatment evaluation. Recently, distinct genetic effects on preparation and response control or impulsivity were detected using the CPT. As such, the task remains a valuable tool for further investigations of genetic and environmental factors of ADHD.
\end{abstract}

Keywords Attention deficit hyperactivity disorder (ADHD) Continuous performance test (CPT) - Inattention .

Preparation - Omission and commission error · Cue-P3 . $\mathrm{CNV} \cdot \mathrm{NoGo}-\mathrm{P} 3 \cdot$ Endophenotype $\cdot$ Genetic

This article is part of the Topical Collection on $A D H D$

B. Albrecht $(\triangle) \cdot$ H. Uebel-von Sandersleben $\cdot$ K. Wiedmann · A. Rothenberger

Department of Child and Adolescent Psychiatry, University Medical Center Göttingen, von Siebold Straße 5, 37075 Göttingen, Germany

e-mail: balbrec@gwdg.de

\section{Introduction}

Severe and age-inappropriate levels of hyperactivity, impulsivity, and inattention present in more than one area of life, now referred to as attention deficit hyperactivity disorder (ADHD), is one of the most frequently observed psychiatric disorders [1]. Although the theoretical conception and diagnostic criteria of ADHD have undergone several modifications, the core symptoms have long been known.

In this selective review, we illustrate a part of the history of ADHD in the context of research on sustained attention, preparation, and response control using the continuous performance test (CPT). The following section gives a brief overview of the history of the ADHD concept, followed by a short clinical characterization. The second section of the manuscript introduces the CPT, which was used early on as a test of sustained attention and vigilance for the diagnosis of patients with brain damage. We will illustrate that important aspects of ADHD core symptoms such as impulsivity and inattention can be captured with the CPT on levels of task performance data and brain activity measures. This renders the CPT a valuable paradigm for testing current theories of ADHD, identifying genetic and environmental risk factors, and further elucidating the pathophysiology of the disorder.

\section{Attention Deficit Hyperactivity Disorder}

ADHD: History of the Concept in a Nutshell

Various descriptions of children with behavioral problems, seemingly characterized by hyperkinetic symptoms, date from the mid-nineteenth century [2], and CPT demands such as sustained attention and response control were considered very early on. Heinrich Hoffmann's popular children's book Struwwelpeter (Shockheaded Peter), first published in 1845, 
gives an early differentiation of two subtypes, predominant hyperactivity (the "Fussy-Philip") and attention problems (the "Hans Stare-in-the-Air"). As such, ADHD symptoms made their way into literature and paintings as early as the middle of the nineteenth century. The first clear systematic scientific study of hyperactivity was carried out in 1902 by the pediatrician George Frederick Still (1868-1941), who attributed the observed behavioral problems to a "defect of moral control" as the result of an organic injury [3].

Also early in the twentieth century, ADHD-like symptoms were ascribed to brain dysfunctions. Observations of patients with frontal lobe lesions revealed that such injuries resulted in extensive deficits of "executive functions". "Cognitive conflicts" could no longer be resolved, and the patients had a tendency to give in to their primary action impulses, potentially leading to great difficulties in solving everyday life problems. These observations suggested that ADHD could be a milder form of dysfunction in frontal cortical structures [2]. The concepts of "minimal brain damage" (MBD) or "organic restlessness" were introduced, suggesting that milder forms of brain damage might lead to less severe behavioral problems such as ADHD. In 1908, the physician Alfred F. Tredgold postulated that modest hypoxia or other brain damage during birth was the possible cause of hyperkinetic behavioral problems that often became clear with the requirements of the first year of school. Tredgold also believed that the affected children had an inclination toward criminal behavior, even if they grew up in a beneficial environment.

After an epidemic of encephalitis in 1917 and 1918, some of the cured children suffered from behavioral and cognitive problems similar to ADHD core symptoms. These observations in the first half of the twentieth century led to the assumption that hyperactivity disorder may be caused by an organic brain damage, although the validity of this view was later criticized by Schachar, who analyzed case reports from an outbreak of encephalitis from 1918 to 1924 in England, and found clear ADHD symptoms only rarely amongst affected children [4].

In 1932, Kramer and Pollnow published a work on hyperkinetic disorder in children, Hyperkinetischen Erkrankung des Kindesalters, in which they described a syndrome characterized by restlessness, distractibility, and speech developmental disorders. In 1934, Lederer and Ederer described an independent hyperkinetic syndrome, Hypermotilitätsneurose im Kindesalter, as well. The use of terminology such as "postencephalitic behavior disorder" or "minimal brain damage" is evidence that an organic brain deficit was the assumed cause of all of these behavioral problems. The terms were suggested, but neither described nor assessed uniformly, and were never precisely defined [5]. Since the 1950s, the assumption that an organic brain injury such as "minimal brain damage" should be considered the central factor in hyperactivity disorders has been called into question as an impediment to rather than incentive for further research [6].

From the 1960s onward, views regarding ADHD differed between Europe and the United States. In Europe, the condition was considered as rare and related to a brain injury, accompanied by considerable restlessness, while the phenomenon in the United States was considered common, and not necessarily associated with brain injury. In the 1970s, the focus shifted towards the attention aspects of the disorder. Studies reported that children with hyperkinetic symptoms often had great difficulty sustaining attention in task-related activities. Because of the lack of continuous, macroscopically visible neuroanatomical damage, the term MBD was replaced by "minimal cerebral dysfunction (MCD)". However, the unconditional correlation between MCD and behavior was rejected in epidemiological studies, and MCD was henceforth regarded as an organic risk factor for ADHD symptoms [5]. In the 1970s, MCD was thought to be the cause of several cognitive symptoms, including learning disabilities, attention deficit, and developmental problems, as well as hyperactivity.

More recent theoretical approaches have integrated clinical symptoms and neuropsychological difficulties in a framework of more or less specific brain dysfunctions. A number of cognitive theories suggest that ADHD is associated with deficits in executive functions following on from dysfunction in frontostriatal or mesocortical brain networks responsible for attention and response organization [7, 8]. A classical approach proposed by Barkley suggested behavioral inhibition as the core deficit leading to problems with working memory, self-regulation, internalization of speech, and reconstitution, which are characteristic of ADHD [9]. Numerous studies have reported deficits in tasks tapping executive functions. Although there is much highly supportive evidence of differences between groups of patients with ADHD and controls, many patients do not show significant impairment in executive functions, while impairments have been observed in several controls that show no ADHD symptoms [10].

In contrast, earlier motivational theories like SonugaBarke's delay aversion theory [11] and Sagvolden's theory of impaired reward processing due to a shorter and steeper delay-of-reinforcement gradient [12] highlight that performance problems in ADHD may also origin from motivation problems. Such deficits were later associated with dysfunctions in the mesolimbic dopaminergic system, including the ventral tegmentum and nucleus accumbens, which is in good agreement with fMRI studies showing lower activity in the ventral striatum, including nucleus caudatus, nucleus accumbens, and putamen, in ADHD during reward anticipation $[13 \bullet \bullet]$.

Cognitive and motivational theories are not necessarily contradictory, but rather may supplement each other, as suggested in the syntheses described in later "multiple pathway" theories associating cognitive and motivational 
deficits in ADHD with dysfunction in distinct neural networks $[14,15]$. This has recently been put forward in an approach considering connectivity between brain regions, suggesting that in ADHD in particular, default mode network activity may interfere with activity in a number of neural networks responsible for visual attention, orientation, executive control, or motor activity $[16,17 \bullet \bullet]$.

\section{Clinical Characteristics}

In the DSM-III (1980), attention problems and hyperactivity were classified as "attention deficit disorder with hyperactivity (ADDH), which requires the core symptoms of inappropriate levels of inattention, hyperactivity, and impulsivity beginning before the age of 7 years and present for at least six months in more than one area of life; and ADD, a subtype diagnosed without hyperactivity. The revised DSM-III-R (1987) introduced a list of 14 symptoms to clarify and improve diagnostic criteria. The DSM-IV released in 1994 distinguishes ADHD subtypes characterized predominantly by attention problems from individuals with hyperactivity and impulsivity, as well as a combined type fulfilling criteria for both inattention and hyperactivity/impulsivity [18]. The recently released DSM$\mathrm{V}$, which considers ADHD as a neurodevelopmental disorder, eased the age of onset criterion towards 12 years and clarified diagnostic criteria for ADHD in adults [1]. In any case, the symptoms must be manifest from childhood for more than six months in at least two areas of life [19].

With a prevalence of approximately $5 \%$ in children and adolescents, and high persistence leading to $3 \%$ prevalence in adults, ADHD is one of the most frequently diagnosed disorders in psychiatry [20, 21]. It is associated with lower educational, social, and clinical outcomes in adulthood, rendering ADHD a lifelong problem, even in the case of early remission [22••]. ADHD is much more prevalent among family members of patients, which must be considered for diagnosis and treatment $[23,24]$. Twin studies in childhood showed high heritability estimates of more than $70 \%$ explained symptom variance due to genetic factors $[25,26]$, suggesting a strong genetic background for the development and persistence of the disorder.

\section{The Continuous Performance Test}

The history of the CPT originates in the middle of the twentieth century with the work of Rosvold et al. (1956). In search of a paradigm sensitive to problems with lapses of sustained attention in individuals with brain damage, the authors suggested a task requiring sustained attention for up to 10 minutes of assessment [27]. This was in stark contrast, for example, to digit span or digit symbol substitution tests frequently used to measure attention or alertness, which usually cover shorter periods of time and may not detect shorter lapses of attention, such as those expected in patients with brain damage.

Figure 1 provides a general overview of this approach. In brief, a sequence of letters is presented, and participants are instructed to press a button if the target letter (e.g., the letter "X") is presented, but to withhold the response in all other instances. The simplest version requires a response to each target letter, and to withhold the response to all other stimuli (see Fig. 1, left side). This "CPT-X" is similar to a go/no-go task, but incorporates a lower target rate, and consequently does not help in maintaining activation or inducing a strong "prepotency" to respond. A more difficult extension of this paradigm as initially presented by Rosvold (1956) requires a response only if the target letter is preceded by a cue (e.g., the letter "A") (see Fig. 1, right side). This cued "CPT-AX" can also be used to assess response preparation, which may be a smart move, particularly in research on ADHD.

In the original study, a moderate time pressure was introduced by a presentation rate of one stimulus per second, and the procedure was able to differentiate groups of children and adults with brain damage from healthy controls [27]. A subsequent study, which in addition to patients with brain damage in the Rosvold et al. study included individuals with other psychiatric conditions, revealed that the CPT may also be sensitive for attention problems in psychotic patients [28].

\section{The CPT in Research on ADHD}

Since problems with sustained attention were expected in ADHD, the CPT paradigm was adopted early on for research and diagnosis. In the following sections, we describe some historical trends in ADHD research using the CPT.

Early studies dwell particularly on the neuropsychological characteristics of CPT performance, and address important moderating characteristics of the task in research on ADHD.

\section{CPT-X}

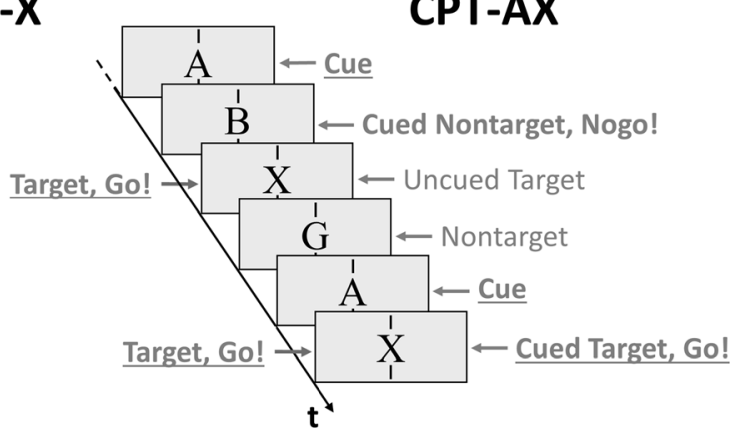

Fig. 1 Description of the Continuous Performance Test. The continuous performance test comprises a sequence of letters, usually presented in the central visual field. In the case of the CPT-X (left), a response is required to all targets (letter "X"), while the CPT-AX requires a response to cued targets only (right) 
Later, brain activity associated with task performance came into focus, and was assessed with increasing spatial and temporal resolution using event-related potential (ERP) and functional magnetic resonance imaging (fMRI) paradigms, unravelling the time course and implicated structures during CPT performance. This parallels advances in the theoretical consideration of ADHD as a (heterogeneous) disorder associated with specific brain dysfunctions. The task was also used for the evaluation of treatment effects, beginning with pharmacological interventions, but later also psychotherapeutic interventions such as attention training and neurofeedback were assessed. Finally, the CPT was used in genetic studies, suggesting that it may uncover specific genetic effects on impulsivity, as well as preparation and response inhibition, which may be relevant for ADHD and other psychiatric disorders sharing similar underlying deficits.

\section{Neuropsychological Characteristics}

Performance in the CPT at the behavioral level is often characterized by reaction time to targets (indexing some general processing speed), errors of omission (e.g., no response to targets, often regarded as inattention), and errors of commission (false alarms to non-targets, often regarded as indicators of impulsive responses). Errors of omission in the cued CPTAX were later further subdivided by Halperin et al. (1989) into (a) false alarms to cued non-targets (A-not-X, often faster than correct responses, possibly a better indicator of impulsivity), (b) false alarms to uncued targets (X-only, often with longer latency, potentially associated with inattention as a result of the preceding stimulus), (c) responses to the cue (in the case of longer latency, potentially premature responses indexing the inability to wait, thus possibly also related to impulsivity), and (d) random errors (present particularly in ADHD, but of unclear origin). In non-referred children, omission and Xonly errors were associated with higher teacher-rated inattention, whereas A-not-X commission errors were associated with elevated hyperactivity and impulsivity ratings [29]. Thus the CPT, particularly in the AX variant, has shown striking face validity for assessing symptoms of inattention and impulsivity under controlled conditions.

Early studies, however, have raised doubts as to whether the CPT can be used for the diagnosis of ADHD. Although a high percentage of children with ADHD may exhibit performance problems, control children may also show impairment without the presence of ADHD symptoms, and conversely, some children with ADHD may not show impairment in the CPT $[10,30]$. Because sensitivity and specificity for ADHD may both be below $70 \%$, CPT performance parameters are not recommended for individual diagnosis [31]. Moreover, despite replication of substantial group differences between patients with ADHD and controls, the key CPT performance parameters may not be specifically related to core symptoms of ADHD in patients [32].

An initial narrative review based on studies from the 1970s to 1990 was critical of the CPT. The authors showed that the task was far away from an ideal instrument for ADHD research; it lacked a sound theoretical basis and thorough investigation of mediating factors such as developmental effects (the authors suggested a strong improvement in sustained attention between the ages of 4 and 6 years), task variables (stimulus onset time, event rate, task duration), and situational factors (time of day during assessment, medication, or noise) for the interpretation of performance data [33]. For example, the target detection rate may be related to the event rate in an inverted $\mathrm{U}$ shaped manner: a higher event rate (more than one event per second) may lead to over-activation and induce time pressure, leading to a lower target detection rate, with a performance maximum of one event in two seconds and lower detection rate if an event occurs only every four seconds, which is particularly pronounced in children with ADHD [34]. Moreover, the target rate (often ranging from $10 \%$ to $25 \%$ in a CPT) may influence the prepotency to respond, and deficits in vigilance or sustained attention may be particularly present with an extended time on task, all of which may influence group differences between ADHD and controls. In lieu of heterogeneous ADHD effects on key CPT performance parameters discussed thus far (which may, in addition to all of these uncontrolled moderators, reflect poor statistical power), Corkum and Siegel have suggested a cognitive energetic model, including psychological resource arousal, activation, and effort that may play a role in ADHD [33, 35]. Thus, patients with ADHD may be particularly likely to show deficit when their energetic or cognitive and motivational resources are stressed, which may be manipulated in the CPT implementation, e.g., by event rate, target frequency, or presence of incentives, a concept that should be considered in further studies.

Potential vigilance deficits in ADHD were revisited in a recent meta-analysis by Hunag-Pollock (2012). The authors aggregated studies published from 1995 to 2010 that had not been covered by earlier studies [33, 36]. Inclusion criteria were limited to studies assessing samples of children with ADHD and normally developing controls, predominantly aged 6 to 12 years, with a CPT of less than $50 \%$ target probability (separating the CPT from go/no-go tasks specifically tapping response control), which controlled a number of moderators identified in the earlier review by Corkum et al. (1993), suggesting that the aggregated studies are particularly sensitive for ADHD difficulties. In total, more than 30 studies comprising more than 3,000 participants reported errors of commission and omission, 26 studies including more than 1 , 300 subjects assessed mean reaction time, and 16 studies reported intra-individual standard deviation of reaction time. All of these parameters indicated CPT performance problems in ADHD of large effect size, but also confirmed a number of 
potential moderators. It was determined that ADHD problems with mean response speed were more pronounced in CPTs with more frequent targets, effects on omission errors were larger in older children, and ADHD effects on RT-SD were more frequent in studies with a larger proportion of males [37•]. However, only a few studies assessed time-on-task effects, which may provide further insights into ADHD. In sum, the children with ADHD may show moderate to significant difficulty with sustained attention and impulsivity in CPTs with moderate event rates and rare targets.

Another early application of the CPT in ADHD was the evaluation of treatment using MPH. A meta-analysis on CPT error rates by Losier et al. (1996) applied rigorous selection criteria (limited to high-quality studies published between 1973 and 1995 on children aged 6 to 12 years, addressing case-control differences and effects of MPH in ADHD in thoroughly diagnosed samples) and aggregated effect size across studies. The authors confirmed higher omission and commission error rates in children with ADHD, which were considerably improved following administration of MPH [36]. Beneficial MPH effects on error rates as well as response speed were confirmed in a later narrative review, further suggesting that administration of dextroamphetamine may also yield improvements [38]. In addition, the CPT was used for the evaluation of improved pharmaceutical dosage forms of MPH, e.g., extended controlled-release capsules [39]. It was recently demonstrated that atomoxetine (ATX, a nonstimulant selective norepinephrine reuptake inhibitor used for the treatment of ADHD in children and adults) may lead to improved CPT performance, albeit of a smaller magnitude than with MPH [40, 41].

In addition to the evaluation of pharmacological treatments in ADHD, the CPT was recently used for identifying drug response. This was demonstrated for a response criterion of at least $25 \%$ improvement in the ADHD Rating Scale-IV after six weeks of treatment, where the response rate was significantly diminished in children older than 10 years with extremely low reaction times (below the fifth percentile) in the CPT [42], although the validity of such effects needs to be replicated in further studies. While MPH effects may be visible to the naked eye within 30 minutes after administration, the prognosis of response to treatment could be particularly important for agents like ATX, which may reach full effectiveness in ADHD after several weeks of treatment [43], although studies are currently lacking.

The CPT has also been used for the evaluation of nonpharmacological interventions in ADHD. One key example is in the area of neurofeedback training, which has been shown to be effective on symptom ratings and neuropsychological task performance, including the CPT [44•, 45].

In sum, the CPT may uncover difficulties in ADHD under controlled assessments, and may thus be used for treatment evaluation.
The majority of the above-mentioned neuropsychological findings were obtained from laboratory experiments under well-controlled - albeit often not very naturalistic - conditions. Assessment of CPT performance outside the laboratory was undertaken by Bart et al. (2014), who administered the CPT online, with good reliability, although the performance was generally lower than that during laboratory testing [46]. It remains to be seen whether the advantages of assessing potentially large samples in situations where ADHD problems are eminent can outweigh the pitfalls of lower experimental control over the variables described above in moderating CPT performance.

Another promising approach was demonstrated with the implementation of the CPT in a virtual reality environment, transferring CPT demands into standardized everyday life situations. This technique was utilized by Pollak et al. (2009) in children with ADHD, in which a CPT-AX was presented within a virtual classroom with audio-visual distractors (classroom noise, a flying airplane, or a car rumbling outside the classroom window). The virtual environment CPT yielded similar case-control effect sizes as the classical CPT from the Test of Variables of Attention (T.O.V.A.) [47], and was also sensitive to MPH treatment effects [48]. This approach may afford the opportunity to conduct assessments with higher ecological validity without losing experimental rigor. Further experiments should assess the influence of naturalistic distractors on performance in healthy controls as well as patients with ADHD.

\section{Psychophysiological Characteristics}

Assessment of brain activity parameters has been used to identify impairment in CPT performance in ADHD on the basis of neural inhibition. In the last two decades, studies in ADHD have focused on the assessment of brain electrical activity evoked by the CPT (for an overview, see [49]) as well as assessment via functional magnetic resonance imaging (fMRI).

Brain activity corresponding to changes in the bloodoxygen-level-dependent (BOLD) contrast during CPT performance can be detected with fMRI assessment utilizing high spatial resolution [50]. These studies suggest that the CPT leads to activations in basal ganglia, prefrontal, and parietal attentional systems including middle frontal and dorsolateral prefrontal cortex, anterior cingulate cortex [ACC], and precuneus, which are implicated in several "dopaminergic" psychiatric disorders [51, 52].

Children with ADHD showed performance and activation deficits in fronto-striato-parieto-cerebellar brain networks in the go/no-go contrast during an uncued rewarded CPT, which was normalised in temporal and parietal regions after administration of MPH [53]. Adults with ADHD were characterized by reduced fronto-striatal and left parietal activation during 
no-go trials of a relatively fast-paced CPT-AX; in addition, impulsivity was related to lower activity in the caudatum and ACC but increased activity in the left insular cortex [54].

In electrophysiological recordings during task performance, neural activity can be tracked as event-related potential (ERP) with high temporal resolution $[49,55]$, uncovering the activity of information processing during CPT performance (see Fig. 2). Early ERP components such as P1/N1, generated within the first $200 \mathrm{~ms}$ after stimulus presentation in the primary sensory cortices, are sensitive to physical characteristics of the stimuli but may be further modulated by early attention, while later components may reflect higher cognitive processing of particular interest for CPT performance in ADHD.

Cues elicit after 300-1,000 ms a broad positive deflection, which is maximal over parietal scalp areas. This Cue-P3 may be generated in posterior attentional networks associated with attentional orienting and resource allocation, and it may be reduced in amplitude in children and adults with ADHD [56-58]. The Cue-P3 is followed by a negative slow cortical potential maximal over the vertex that terminates with the presentation of the next stimulus (contingent negative variation, CNV) [59]. The CNV has been linked to timing and temporal memory $[60,61]$, and may be crucial for preparation in the CPT. Neurophysiological studies have implicated an ensemble of thalamocortical structures involved in CNV generation including the dorsal anterior cingulate cortex, frontal cortex, thalamus, and midbrain dopaminergic nuclei involved in CNV generation [62-64]. Numerous studies have demonstrated that $\mathrm{CNV}$ amplitude may be reduced in ADHD [56, 65-68] and may represent a persistent deficit in patients with ADHD [69・•], although there have also been some negative findings $[58,70,71]$.

In trials following such cues, response control is required, and the difference in task demand between go and no-go trials is paralleled in the ERP. Following enhanced N2 amplitude in no-go trials indexing action monitoring processes (which may be less challenging in the CPT compared to stop signal or flanker tasks, and often do not reveal deficits in ADHD) [72], the subsequent P3 is also modulated: cued distractors that do not require execution of a prepared response evoke a no-go $\mathrm{P} 3$ maximal at fronto-central sites. Studies with more responseinhibition-demanding Go/No-Go tasks suggest that it may reflect response inhibition [73-75], but since its latencies often exceed typical go reaction times, it may rather indicate termination of motor activation through a lapse of cortical excitation in motor areas when nothing more is left to do $[74,76,77]$. Clearly, these aspects are interrelated, and thus No-Go-P3 may be generated by several processes of terminal response control in the medial or anterior cingulate cortex, premotor areas, and frontal areas, likely following dopaminergic input from basal ganglia [78-82]. Clinical studies have shown that no-go P3 was altered in amplitude or
Fig. 2 Event-Related Potentials Evoked by the CPT-AX. Electrophysiological characteristics of CPT-AX performance at midline electrodes from typically developing children. Stimulus processing is characterized by early $\mathrm{P} 1 / \mathrm{N} 1$ components generated in primary and secondary visual areas, which are particularly elevated for the occipital $\mathrm{N} 1$ (with a positive amplitude at Fz after $200 \mathrm{~ms}$ ) during cue processing (red). The $\mathrm{N} 2$ associated with cognitive control (with a fronto-central maximum after approx. $300 \mathrm{~ms}$ latency) is larger for cued No-Go (green) than Go (blue) trials, while the parietal P3 to task-relevant cues and cued targets is maximal over parietal sites. Cues elicit a slow wave contingent negative variation associated with preparation (consequently also present preceding cued No-Go and Go trials), which is not evoked by distractors (black). Further details are provided in [96]

anteriorization in patients with ADHD and may, like CNV, represent a persistent neurophysiological deficit [69••, 83, 84], although similar effects are present in a wide range of other disorders such as Parkinson's [85] and Huntington's [82] diseases.

The more parietally distributed Go-P3 has been associated with several attentional functions such as evaluation of stimuli, closure, and resource allocation [86, 87], and may thus reflect executive response control. Explicit analyses of Go-P3 evoked by the CPT in ADHD are rare, but some instances of diminished amplitude in patients have been observed [70, 72, 88, 89].

In addition to clarification of neural dysfunctions in ADHD, early studies on brain electrical activity during CPT performance were conducted to evaluate the impact of methylphenidate medication. Studies showed that MPH ameliorated CPT-X performance and led to increased N2 and P3 amplitudes to targets and non-targets in children with ADHD $[90,91]$. However, these earlier investigations were often limited by relatively small sample size (often less than 15 participants per sample) and a relatively poor spatial resolution of the recorded signals due to a low number of recorded sites (often less than 10). Limitations of sample size were overcome by the use of multicentre studies [58], and advances in amplifier technology allowed high-density recordings with 32 channels, as well as detailed assessment of topography during stable micro states in brain mapping approaches [92].

CPT was later used to differentiate ADHD subtypes or frequent comorbidities. For example, a study from our lab revealed that children with comorbid ADHD and oppositional defiant or conduct disorder (ODD/CD) were characterized by less abnormal performance, Cue-P3, and -CNV than suggested by an additive model of impairments found in children with pure ADHD and ODD/CD symptoms [56].

\section{Genetics}

Although heritability estimates of $70 \%$ explained symptom variance in twins suggest a strong genetic impact on ADHD, association with candidate genes were rather moderate, and 


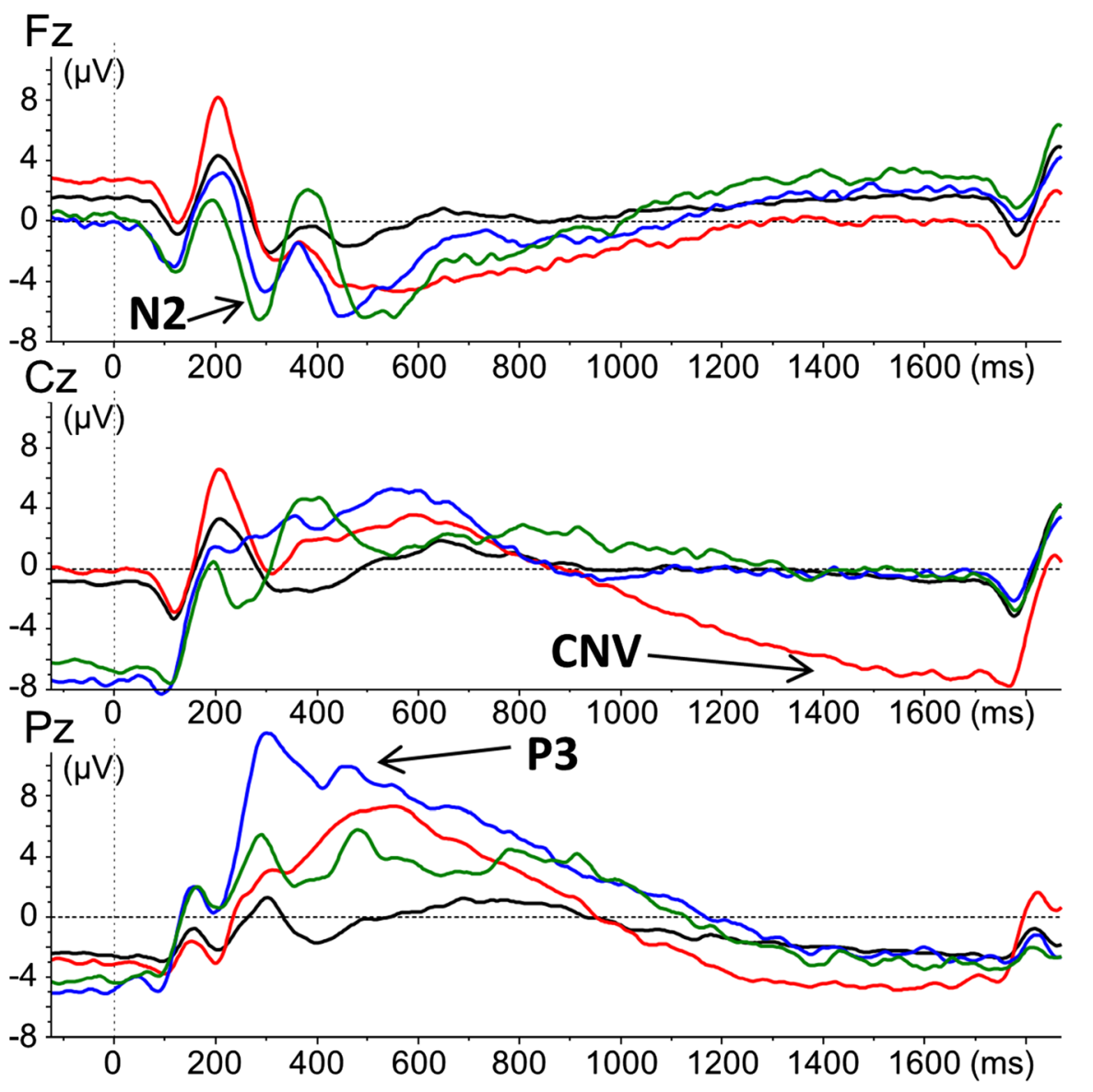

N2
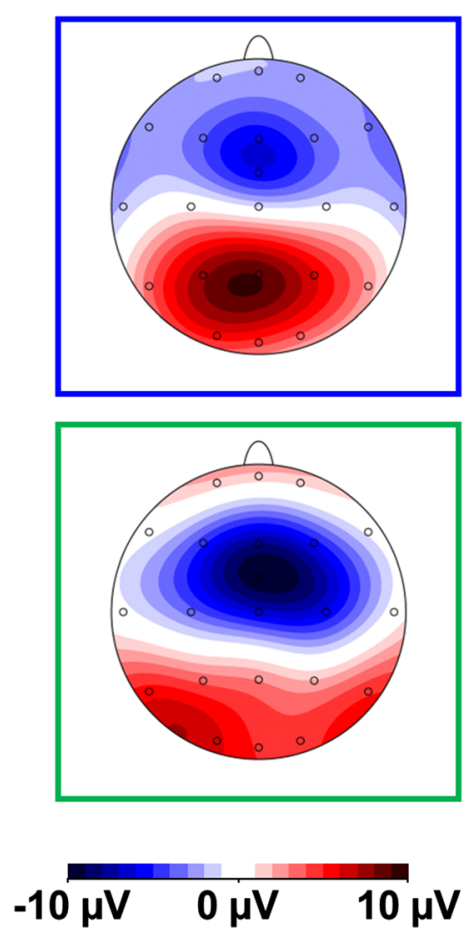

P3
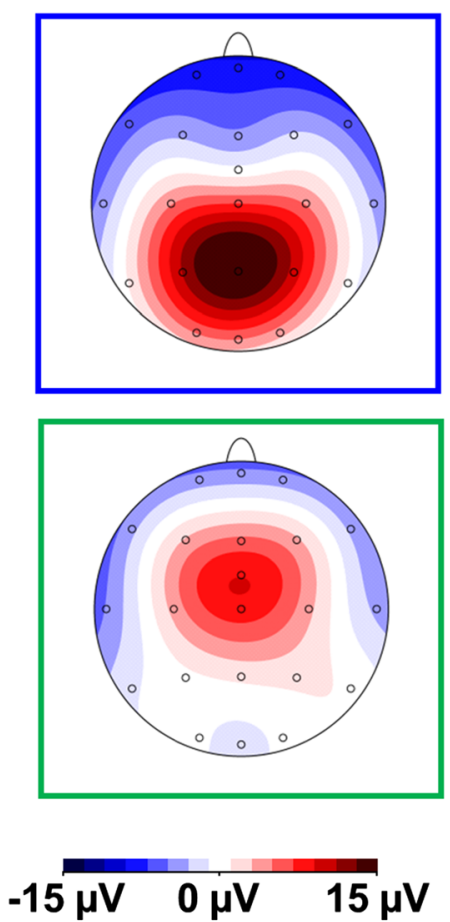

Cue

Cued Target

Cued Nontarget

Distractor
CNV
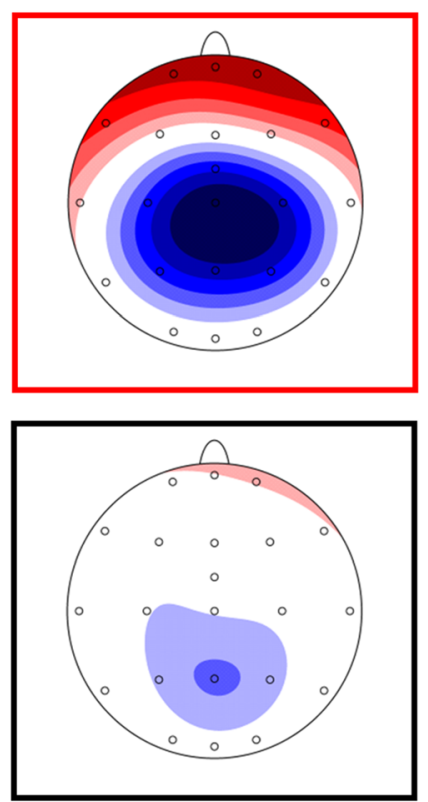

$-6 \mu \mathrm{V} \quad 0 \mu \mathrm{V} \quad 6 \mu \mathrm{V}$ 
genome-wide association scans (GWAS) thus far have revealed no significant effects. This may suggest that ADHD is a genetically heterogeneous disorder on which frequent variants have a very small effect (potentially less than $0.5 \%$ explained variance), while variants with larger effects are likely rare, and the situation may be complicated by genegene and gene-environment interactions and may be further moderated by epigenetic influences $[25,93 \bullet \bullet, 94]$.

Endophenotypes, which are characterized by more fundamental biological properties between genetic or environmental risk factors and the phenotype, may help to clarify these associations through potentially larger and more specific genetic effects, and may thus offer advantages for molecular genetic studies [95]. In many cases, risk factors are expected to be shared within families, suggesting that non-affected relatives show some (milder) impairments in these parameters. This was demonstrated with the CPT in studies during childhood and adolescence, where boys with ADHD as well as their non-affected siblings showed diminished brain activity related to preparation (Cue-P3 and -CNV) and response inhibition (no-go P3) compared to controls without a family history of ADHD [96]. Cue-P3 and No-Go-P3 remain familial-driven during adulthood [97], and a familial transmission of CPT commission errors between parents and children has also been demonstrated [98], suggesting that the CPT may uncover endophenotypes for ADHD.

Studies on the impact of certain candidate genes specifically related to the dopaminergic system on CPT performance or associated brain activity have spanned nearly the last decade, and have elucidated the impact of various candidate genes. This has been illustrated for the dopamine receptor D4 (DRD4) and dopamine transporter (DAT1) genes.

The DRD4 gene is located on chromosome 11p15.5. It modulates the D2-like receptor, which is particularly present in the frontal lobe and the orbitofrontal and anterior cingulate cortex [99, 100]. It has a variable number of tandem repeats (VNTR) between 2 and 10, of which 2, 4, and 7 are most common in humans. The 7-repeat (7R) polymorphism in particular is less sensitive to dopaminergic stimulation [101, 102]. Recent meta-analyses suggest that DRD4 7R is also moderately associated with ADHD [25, 99, 103, 104] and novelty-seeking [105], which highlights the role it may play in attention and motivation.

In an early study using an uncued CPT implemented in T.O.V.A. in children with ADHD, increased impulsivity as measured by commission errors was significantly associated with the shorter (shorter than 7-, and particularly 2-repeat) variants of the DRD4 gene (as well as with the long polymorphism of the monoamine oxidase gene A [MAO-A]), which was ameliorated by methylphenidate [106, 107]. Importantly, the studies by Manor et al. used the uncued CPT as implemented in T.O.V.A., which did not tap preparation processes. Moreover, the authors found (and replicated) the short DRD4 alleles associated with ADHD in their sample from Israel, which is in contrast to findings from other samples. Thus further research is needed in order to interpret these "paradoxical" findings that an ADHD risk allele was associated with fewer impulsivity errors in the CPT.

A larger study in patients with ADHD carrying the DRD4 7R allele revealed faster and more error-prone responses in the Matching Familiar Figures Test and lower response speed in the stop task, but no DRD4 effects were detected in the go/no-go task or the CPT [108]. Unfortunately, details regarding the CPT procedure used were not provided, but it was likely an implementation without cues that require a response if a stimulus is repeated.

DRD4 polymorphisms also had an impact on error rates in a simplified CPT requiring a response to a target from a sequence of numbers. Children with ADHD carrying at least one $7 \mathrm{R}$ allele showed more commission errors, while children homozygous for the $4 \mathrm{R}$ allele showed protective effects and made fewer errors of commission and omission [109].

A more recent study with a cued CPT found evidence that the DRD4 7R variant may be associated with inattention as reflected in omission errors, which is dissociated from the impact of the DAT1 gene (see below) [110]. A recent study from our lab with a cued CPT was consistent with Gizer and Waldman's findings regarding performance (children with DRD4 7R showed slower and more heterogeneous reaction times), as well as preparation problems as indicated by lower Cue-P3 and -CNV amplitude [111]. Importantly, these DRD4 effects were similarly present in children with ADHD and controls, and explained approximately a $4-5 \%$ variance.

In sum, the impact of DRD4 polymorphisms on the CPT appears to be heterogeneous, depending on the task variant applied. While studies with the more difficult cued CPT-AX detected attention and preparation problems in carriers of the $7 \mathrm{R}$ allele, the simpler uncued CPT-X revealed results that are less clear. This is consistent with the well-known clinical impression that children with ADHD show more difficulties when the going gets tough.

The dopamine transporter gene (DAT1, SLC6A3) codes the carrier protein responsible for the reuptake of dopamine from the synaptic cleft, particularly in the mesolimbic (including ventral tegmentum and nucleus accumbens, and associated with reward processing) and mesocortical (also starting in the ventral tegmentum with projections to the prefrontal cortex, associated with arousal and various attention problems) dopamine systems $[112,14]$. This may explain why methylphenidate, which 
blocks the dopamine transporter, resulting in higher levels of available dopamine in the synaptic cleft, has such a widespread and immediate impact on ADHD symptoms [113]. The DAT1 gene has two commonly studied VNTR polymorphisms of 9 or 10 repeats of a 40-basepair sequence in the 3' untranslated region (UTR), but the effect of these polymorphisms on the dopamine transporter functioning, and associations with ADHD in particular, remain inconclusive [104], which may be explained by developmental or environmental effects [114]. As such, the 10-repeat (10R) allele may be a risk factor for childhood ADHD, while the 9-repeat polymorphism has been associated with persistent ADHD in adults [115].

There is some evidence linking DAT1 10R to impulsivity. An early study with an uncued CPT detected more heterogeneous response speed, more commission errors, and a more impulsive response style in children homozygous for the 10R [116]. This in in line with problems with selective attention and response inhibition detected in children homozygous for the 10R allele [117]. However, a Korean sample in ADHD children with DAT 9R showed more commission errors [118].

The aforementioned study by Gizer and Waldman with cued CPT also revealed elevated commission errors, indicating higher impulsivity in children with the DAT1 10R allele.

Findings from our study may complement these results, as children with the DAT1 10-6 haplotype did not show higher commission error rates; rather (potentially as a compensatory mechanism) the No-Go-P3 amplitude as an electrophysiological marker of response inhibition was higher [111]. This demonstrates that accessory analysis of brain activity may uncover potentially compensatory neural processes that may lead to normal overt performance.

Studies in adults appear to be less consistent. One study on CPT performance in healthy participants with the 10R allele showed faster response speed and more commission errors (and thus a rather impulsive response style) [119], while another EEG study revealed no clear performance differences, but less no-go P3 anteriorization specifically in patients with ADHD [120].

Taken together, studies on the impact of DRD4 and DAT1 polymorphisms on CPT performance and associated brain activity have yielded mixed results. This may be at least partially explained by differences in the CPT implementation, particularly the time pressure induced by shorter inter-stimulus intervals and whether the CPT includes cues. In the first instance, the DRD4 7R polymorphism may lead to preparation problems related to cue processing that may result in diminished responses to the adjacent targets. The impact of DAT1 variants may vary with age groups and the population assessed, but the $10 \mathrm{R}$ variant may be associated with impulsivity or compensatory response inhibition in children. Importantly, genetic effects in children explained about $4 \%$ to $5 \%$ variance in performance and electrophysiological brain activity parameters of preparation and response control, which is much greater than associations with ADHD detected in GWAS thus far, indicating that endophenotypes based on brain activity may be a promising approach for understanding the role of genetic and environmental factors on ADHD and other psychiatric disorders.

\section{Conclusions}

The understanding of ADHD has undergone a number of important changes. Brain dysfunctions were proposed as early as the beginning of the twentieth century. The CPT, introduced for the diagnosis of vigilance or sustained attention problems in patients with brain damage, was consequently applied early on in ADHD research, and has been a valuable tool for the assessment of cognitive and motivational deficits in ADHD. Future applications include treatment evaluation and differentiation of ADHD subtypes and associated or comorbid disorders. Early studies characterized CPT performance at the behavioral level with regard to omission and commission errors, response speed, and signal detection parameters. Subsequently, brain activity was assessed using fMRI and ERP to uncover activity in neural networks associated with attention, preparation, and response control. Further studies on genetic as well as epigenetic influences may lead to a deeper understanding of information processing in the brain and problems associated with ADHD.

Taken together, the CPT has helped to uncover important pieces of the ADHD puzzle, and is still useful for current research. The joint history of ADHD and CPT may explain the ongoing interest in a heritage task from the middle of the last century, suggesting that both concepts may outlast many researchers currently working on them.

\section{Compliance with Ethics Guidelines}

Conflict of Interest Katharina Wiedmann and Björn Albrecht have no potential conflict of interest to declare. Henrik Uebel-von Sandersleben received conference attendance support or was paid for public speaking by Eli Lilly and Company, Janssen-Cilag, Medice, Novartis, and Shire. Aribert Rothenberger is on the advisory board and speakers' bureau of Eli Lilly and Company, Medice, Novartis, and Shire; and has received educational grants from Medice and Shire; has received research support from Schwabe and Shire, as well as from the German Research Society.

Human and Animal Rights and Informed Consent This article does not contain any studies with human or animal subjects performed by any of the authors. 


\section{References}

Papers of particular interest, published recently, have been highlighted as:

- Of importance

•- Of major importance

1. APA. Diagnostic and statistical manual of mental disorders, fifth edition, DSM-5. Arlington: American Psychiatric Association; 2013.

2. Rothenberger A, Neumärker KJ. Wissenschaftsgeschichte der ADHS - Kramer-Pollnow im Spiegel der Zeit. Darmstadt: Steinkopf Verlag; 2005.

3. Still GF. Some abnormal psychical conditions in children: excerpts from three lectures. J Atten Disord. 2006;10(2):126-36. doi:10.1177/1087054706288114.

4. Schachar R. Hyperkinetic syndrome: historical development of the concept. In: Taylor E, editor. The overactive child. London: Spastics International Medical Publications; 1986.

5. Rothenberger A. Klassifikation und neurobiologischer Hintergrund des hyperkinetischen Syndroms (HKS). Aggressive und hyperaktive Kinder in der Therapie. Berlin: Springer; 1988. p. 5-26.

6. Goodman R, Scott S, Rothenberger A. Kinderpsychiatrie kompakt. 1997.

7. Biederman J. Attention-deficit/hyperactivity disorder: a selective overview. Biol Psychiatry. 2005;57(11):1215-20.

8. Pennington BF, Ozonoff S. Executive functions and developmental psychopathology. J Child Psychol Psychiatry Allied Discip. 1996;37(1):51-87.

9. Barkley RA. Behavioral inhibition, sustained attention, and executive functions: constructing a unifying theory of ADHD. Psychol Bull. 1997;121(1):65-94.

10. Nigg JT, Willcutt EG, Doyle AE, Sonuga-Barke EJ. Causal heterogeneity in attention-deficit/hyperactivity disorder: do we need neuropsychologically impaired subtypes? Biol Psychiatry. 2005;57(11):1224-30. doi:10.1016/j.biopsych.2004.08.025.

11. Sonuga-Barke EJ, Taylor E, Sembi S, Smith J. Hyperactivity and delay aversion-I. The effect of delay on choice. J Child Psychol Psychiatry Allied Discip. 1992;33(2):387-98.

12. Sagvolden T, Aase H, Zeiner P, Berger D. Altered reinforcement mechanisms in attention-deficit/hyperactivity disorder. Behav Brain Res. 1998;94(1):61-71.

13.• Plichta MM, Scheres A. Ventral-striatal responsiveness during reward anticipation in ADHD and its relation to trait impulsivity in the healthy population: a meta-analytic review of the fMRI literature. Neurosci Biobehav Rev. 2014;38:125-34. doi:10. 1016/j.neubiorev.2013.07.012. This recent meta-analysis shows that reward processingwas associated with lower brain activity particularly in the ventral striatum in patients, supporting motivational theories in $A D H D$.

14. Sagvolden T, Johansen EB, Aase H, Russell VA. A dynamic developmental theory of attention-deficit/hyperactivity disorder (ADHD) predominantly hyperactive/impulsive and combined subtypes. Behav Brain Sci. 2005;28(3):397-419. discussion -68.

15. Sonuga-Barke EJ. Causal models of attention-deficit/hyperactivity disorder: from common simple deficits to multiple developmental pathways. Biol Psychiatry. 2005;57(11):1231-8.

16. Sonuga-Barke EJ, Castellanos FX. Spontaneous attentional fluctuations in impaired states and pathological conditions: a neurobiological hypothesis. Neurosci Biobehav Rev. 2007;31(7):977-86. doi:10.1016/j.neubiorev.2007.02.005.

17.• Castellanos FX, Proal E. Large-scale brain systems in ADHD: beyond the prefrontal-striatal model. Trends Cogn Sci.
2012;16(1):17-26. doi:10.1016/j.tics.2011.11.007. Castellanos and Proral propose impaired interplay of large neural networks in general and interferences with a default mode network during task performance in particular as a more fundamental dysfunction in ADHD.

18. APA. Diagnostic and statistical manual of mental disorders, fourth edition, DSM-IV. Arlington: American Psychiatric Association; 1994.

19. Kieling C, Kieling RR, Rohde LA, Frick PJ, Moffitt T, Nigg JT, et al. The age at onset of attention deficit hyperactivity disorder. Am J Psychiatry. 2010;167(1):14-6. doi:10.1176/appi.ajp.2009. 09060796.

20. Fayyad J, De Graaf R, Kessler R, Alonso J, Angermeyer M, Demyttenaere K, et al. Cross-national prevalence and correlates of adult attention-deficit hyperactivity disorder. Br J Psychiatry : J Ment Sci. 2007;190:402-9. doi:10.1192/bjp.bp.106.034389.

21. Polanczyk G, Rohde LA. Epidemiology of attention-deficit/hyperactivity disorder across the lifespan. Curr Opin Psychiatry. 2007;20(4):386-92. doi:10.1097/YCO.0b013e3281568d7a.

22.• Klein RG, Mannuzza S, Olazagasti MA, Roizen E, Hutchison JA, Lashua EC, et al. Clinical and functional outcome of childhood attention-deficit/hyperactivity disorder 33 years later. Arch Gen Psychiatry. 2012;69(12):1295-303. doi:10.1001/ archgenpsychiatry.2012.271. Longitudinal studies highlight that childhood ADHD may be associated with life-long educational, occupational, economic, and social problems, and this studyis of particular importance because of the long-term follow-up, detailed assessment and relatively large sample assessed.

23. Biederman J, Faraone SV, Keenan K, Knee D, Tsuang MT. Family-genetic and psychosocial risk factors in DSM-III attention deficit disorder. J Am Acad Child Adolesc Psychiatry. 1990;29(4): 526-33.

24. Faraone SV, Biederman J, Mick E, Williamson S, Wilens T, Spencer T, et al. Family study of girls with attention deficit hyperactivity disorder. Am J Psychiatry. 2000;157(7):1077-83.

25. Faraone SV, Perlis RH, Doyle AE, Smoller JW, Goralnick JJ, Holmgren MA, et al. Molecular genetics of attention-deficit/hyperactivity disorder. Biol Psychiatry. 2005;57(11):1313-23.

26. Lichtenstein P, Carlstrom E, Rastam M, Gillberg C, Anckarsater $\mathrm{H}$. The genetics of autism spectrum disorders and related neuropsychiatric disorders in childhood. Am J Psychiatry. 2010;167(11):1357-63. doi:10.1176/appi.ajp.2010.10020223.

27. Rosvold HE, Mirsky AF, Sarason I, Bransome ED, Beck LH. A continuous performance test of brain damage. J Consult Psychol. 1956;20:343-50.

28. Schein JD. Cross-validation of the continuous performance test for brain damage. J Consult Psychol. 1962;26:115-8.

29. Halperin JM, Wolf LE, Pascualvaca DM, Newcorn JH, Healey JM, O'Brien JD, et al. Differential assessment of attention and impulsivity in children. J Am Acad Child Adolesc Psychiatry. 1988;27(3):326-9. doi:10.1097/00004583-198805000-00010.

30. Trommer BL, Hoeppner JB, Lorber R, Armstrong K. Pitfalls in the use of a continuous performance test as a diagnostic tool in attention deficit disorder. J Dev Behav Pediatr : JDBP. 1988;9(6):339-45

31. American Academy of Pediatrics. Clinical practice guideline: diagnosis and evaluation of the child with attention-deficit/hyperactivity disorder. Pediatrics. 2000;105(5):1158-70.

32. Epstein JN, Erkanli A, Conners CK, Klaric J, Costello JE, Angold A. Relations between Continuous Performance Test performance measures and ADHD behaviors. J Abnorm Child Psychol. 2003;31(5):543-54.

33. Corkum PV, Siegel LS. Is the Continuous Performance Task a valuable research tool for use with children with Attention-DeficitHyperactivity Disorder? J Child Psychol Psychiatry Allied Discip. 1993;34(7):1217-39. 
34. Chee P, Logan G, Schachar R, Lindsay P, Wachsmuth R. Effects of event rate and display time on sustained attention in hyperactive, normal, and control children. J Abnorm Child Psychol. 1989;17(4):371-91.

35. Sergeant JA. Modeling attention-deficit/hyperactivity disorder: a critical appraisal of the cognitive-energetic model. Biol Psychiatry. 2005;57(11):1248-55. doi:10.1016/j.biopsych.2004.09.010.

36. Losier BJ, McGrath PJ, Klein RM. Error patterns on the continuous performance test in non-medicated and medicated samples of children with and without ADHD: a meta-analytic review. J Child Psychol Psychiatry Allied Discip. 1996;37(8):971-87.

37. Huang-Pollock CL, Karalunas SL, Tam H, Moore AN. Evaluating vigilance deficits in ADHD: a meta-analysis of CPT performance. J Abnorm Psychol. 2012;121(2):360-71. doi:10.1037/a0027205. The most recent meta-analysis of CPT performance in ADHD.

38. Riccio CA, Waldrop JJ, Reynolds CR, Lowe P. Effects of stimulants on the continuous performance test (CPT): implications for CPT use and interpretation. J Neuropsychiatry Clin Neurosci. 2001;13(3):326-35.

39. Slama H, Fery P, Verheulpen D, Vanzeveren N, Van Bogaert P. Cognitive improvement of attention and inhibition in the late afternoon in children with Attention-Deficit Hyperactivity Disorder (ADHD) treated with Osmotic-Release Oral System methylphenidate. J Child Neurol. 2014. doi:10.1177/ 0883073814550498.

40. Wehmeier PM, Schacht A, Ulberstad F, Lehmann M, SchneiderFresenius C, Lehmkuhl G, et al. Does atomoxetine improve executive function, inhibitory control, and hyperactivity? Results from a placebo-controlled trial using quantitative measurement technology. J Clin Psychopharmacol. 2012;32(5):653-60. doi:10.1097/ JCP.0b013e318267c304.

41. Bedard AC, Stein MA, Halperin JM, Krone B, Rajwan E, Newcorn JH. Differential impact of methylphenidate and atomoxetine on sustained attention in youth with attention-deficit/hyperactivity disorder. J Child Psychol Psychiatry Allied Discip. 2014. doi: $10.1111 /$ jcpp. 12272.

42. Elliott GR, Blasey C, Rekshan W, Rush AJ, Palmer DM, Clarke S, et al. Cognitive testing to identify children with ADHD who do and do not respond to methylphenidate. J Atten Disord. 2014. doi: 10.1177/1087054714543924.

43. Weiss M, Tannock R, Kratochvil C, Dunn D, Velez-Borras J, Thomason $\mathrm{C}$, et al. A randomized, placebo-controlled study of once-daily atomoxetine in the school setting in children with ADHD. J Am Acad Child Adolesc Psychiatry. 2005;44(7):64755. doi:10.1097/01.chi.0000163280.47221.c9.

44. Arns M, Heinrich H, Strehl U. Evaluation of neurofeedback in ADHD: the long and winding road. Biol Psychol. 2014;95:10815. doi:10.1016/j.biopsycho.2013.11.013. A current overview of Neurofeedback as a promising tool for ADHD treatment.

45. Heinrich H, Gevensleben H, Freisleder FJ, Moll GH, Rothenberger A. Training of slow cortical potentials in attention-deficit/hyperactivity disorder: evidence for positive behavioral and neurophysiological effects. Biol Psychiatry. 2004;55(7): 772-5. doi:10.1016/j.biopsych.2003.11.013.

46. Bart O, Raz S, Dan O. Reliability and validity of the Online Continuous Performance Test among children. Assessment. 2014;21(5):637-43. doi:10.1177/1073191114530777.

47. Pollak Y, Weiss PL, Rizzo AA, Weizer M, Shriki L, Shalev RS, et al. The utility of a continuous performance test embedded in virtual reality in measuring ADHD-related deficits. J Dev Behav Pediatr : JDBP. 2009;30(1):2-6. doi:10.1097/DBP. 0b013e3181969b22.

48. Pollak Y, Shomaly HB, Weiss PL, Rizzo AA, Gross-Tsur V. Methylphenidate effect in children with ADHD can be measured by an ecologically valid continuous performance test embedded in virtual reality. CNS Spectr. 2010;15(2):125-30.
49. Banaschewski T, Brandeis D. Annotation: what electrical brain activity tells us about brain function that other techniques cannot tell us - a child psychiatric perspective. J Child Psychol Psychiatry Allied Discip. 2007;48(5):415-35.

50. Frahm J, Dechent P, Baudewig J, Merboldt KD. Advances in functional MRI of the human brain. Prog Nucl Magn Reson Spectrosc. 2004;44:1-32.

51. Ogg RJ, Zou P, Allen DN, Hutchins SB, Dutkiewicz RM, Mulhern RK. Neural correlates of a clinical continuous performance test. Magn Reson Imaging. 2008;26(4):504-12. doi:10. 1016/j.mri.2007.09.004.

52. Yoon JH, Minzenberg MJ, Ursu S, Ryan Walter BS, Wendelken C, Ragland JD, et al. Association of dorsolateral prefrontal cortex dysfunction with disrupted coordinated brain activity in schizophrenia: relationship with impaired cognition, behavioral disorganization, and global function. Am J Psychiatry. 2008;165(8): 1006-14. doi:10.1176/appi.ajp.2008.07060945.

53. Rubia K, Halari R, Cubillo A, Mohammad AM, Brammer M, Taylor E. Methylphenidate normalises activation and functional connectivity deficits in attention and motivation networks in medication-naive children with ADHD during a rewarded continuous performance task. Neuropharmacology. 2009;57(7-8):640 52. doi:10.1016/j.neuropharm.2009.08.013.

54. Schneider MF, Krick CM, Retz W, Hengesch G, Retz-Junginger P, Reith W, et al. Impairment of fronto-striatal and parietal cerebral networks correlates with attention deficit hyperactivity disorder (ADHD) psychopathology in adults - a functional magnetic resonance imaging (fMRI) study. Psychiatry Res. 2010;183(1):75-84. doi:10.1016/j.pscychresns.2010.04.005.

55. Picton TW, Bentin S, Berg P, Donchin E, Hillyard SA, Johnson Jr $\mathrm{R}$, et al. Guidelines for using human event-related potentials to study cognition: recording standards and publication criteria. Psychophysiology. 2000;37(2):127-52.

56. Banaschewski T, Brandeis D, Heinrich H, Albrecht B, Brunner E, Rothenberger A. Association of ADHD and conduct disorderbrain electrical evidence for the existence of a distinct subtype. $\mathrm{J}$ Child Psychol Psychiatry Allied Discip. 2003;44(3):356-76.

57. McLoughlin G, Albrecht B, Banaschewski T, Rothenberger A, Brandeis D, Asherson P, et al. Electrophysiological evidence for abnormal preparatory states and inhibitory processing in adult ADHD. Behav Brain Funct. 2010;6:66.

58. van Leeuwen TH, Steinhausen HC, Overtoom CC, PascualMarqui RD, van't Klooster B, Rothenberger A, et al. The continuous performance test revisited with neuroelectric mapping: impaired orienting in children with attention deficits. Behav Brain Res. 1998;94(1):97-110.

59. Walter WG, Cooper R, Aldridge VJ, McCallum WC, Winter AL. Contingent negative variation: an electric sign of sensorimotor association and expectancy in the human brain. Nature. 1964;203:380-4.

60. Macar F, Vidal F. The CNV peak: an index of decision making and temporal memory. Psychophysiology. 2003;40(6):950-4.

61. Pfeuty M, Ragot R, Pouthas V. Relationship between CNV and timing of an upcoming event. Neurosci Lett. 2005;382(1-2):10611.

62. Gomez CM, Marco J, Grau C. Preparatory visuo-motor cortical network of the contingent negative variation estimated by current density. Neuroimage. 2003;20(1):216-24.

63. Fan J, Kolster R, Ghajar J, Suh M, Knight RT, Sarkar R, et al. Response anticipation and response conflict: an event-related potential and functional magnetic resonance imaging study. J Neurosci. 2007;27(9):2272-82.

64. Lutcke H, Gevensleben H, Albrecht B, Frahm J. Brain networks involved in early versus late response anticipation and their relation to conflict processing. J Cogn Neurosci. 2009;21(11):217284. doi:10.1162/jocn.2008.21165. 
65. Grunewald-Zuberbier E, Grunewald G, Rasche A, Netz J. Contingent negative variation and alpha attenuation responses in children with different abilities to concentrate. Electroencephalogr Clin Neurophysiol. 1978;44(1):37-47.

66. Hennighausen K, Schulte-Korne G, Warnke A, Remschmidt H. Contingent negative variation $(\mathrm{CNV})$ in children with hyperkinetic syndrome - an experimental study using the Continuous Performance Test (CPT). Z Kinder Jugendpsychiatr Psychother. 2000;28(4):239-46.

67. Banaschewski T, Yordanova J, Kolev V, Heinrich H, Albrecht B, Rothenberger A. Stimulus context and motor preparation in attention-deficit/hyperactivity disorder. Biol Psychol. 2008;77(1):5362.

68. Barry RJ, Johnstone SJ, Clarke AR. A review of electrophysiology in attention-deficit/hyperactivity disorder: II. Event-related potentials. Clin Neurophysiol. 2003;114(2):184-98.

69.• Doehnert M, Brandeis D, Imhof K, Drechsler R, Steinhausen HC. Mapping attention-deficit/hyperactivity disorder from childhood to adolescence-no neurophysiologic evidence for a developmental lag of attention but some for inhibition. Biol Psychiatry. 2010;67(7):608-16. Another longitudianl study, but this one is on electrophysiological parameters indicating persisting performance problems and associated neural processing deficits related to preparation and response control during a CPT-AX.

70. Strandburg RJ, Marsh JT, Brown WS, Asarnow RF, Higa J, Harper R, et al. Continuous-processing-related event-related potentials in children with attention deficit hyperactivity disorder. Biol Psychiatry. 1996;40(10):964-80.

71. Spronk M, Jonkman LM, Kemner C. Response inhibition and attention processing in 5- to 7-year-old children with and without symptoms of ADHD: an ERP study. Clin Neurophysiol. 2008;119(12):2738-52.

72. Banaschewski T, Brandeis D, Heinrich H, Albrecht B, Brunner E, Rothenberger A. Questioning inhibitory control as the specific deficit of ADHD-evidence from brain electrical activity. J Neural Transm. 2004;111(7):841-64.

73. Fallgatter AJ, Strik WK. The NoGo-anteriorization as a neurophysiological standard-index for cognitive response control. Int J Psychophysiol. 1999;32(3):233-8.

74. Falkenstein M, Hoormann J, Hohnsbein J. ERP components in Go/Nogo tasks and their relation to inhibition. Acta Psychol (Amst). 1999;101(2-3):267-91.

75. Pfefferbaum A, Ford JM, Weller BJ, Kopell BS. ERPs to response production and inhibition. Electroencephalogr Clin Neurophysiol. 1985;60(5):423-34.

76. Kopp B, Mattler U, Goertz R, Rist F. N2, P3 and the lateralized readiness potential in a nogo task involving selective response priming. Electroencephalogr Clin Neurophysiol. 1996;99(1):1927.

77. Verleger R, Paehge T, Kolev V, Yordanova J, Jaskowski P. On the relation of movement-related potentials to the go/no-go effect on P3. Biol Psychol. 2006;73(3):298-313.

78. Strik WK, Fallgatter AJ, Brandeis D, Pascual-Marqui RD. Threedimensional tomography of event-related potentials during response inhibition: evidence for phasic frontal lobe activation. Electroencephalogr Clin Neurophysiol. 1998;108(4):406-13.

79. Kiefer M, Marzinzik F, Weisbrod M, Scherg M, Spitzer M. The time course of brain activations during response inhibition: evidence from event-related potentials in a go/no go task. Neuroreport. 1998;9(4):765-70.

80. Weisbrod M, Kiefer M, Marzinzik F, Spitzer M. Executive control is disturbed in schizophrenia: evidence from event-related potentials in a Go/NoGo task. Biol Psychiatry. 2000;47(1):51-60.

81. Fallgatter AJ, Bartsch AJ, Herrmann MJ. Electrophysiological measurements of anterior cingulate function. J Neural Transm. 2002;109(5-6):977-88.
82. Beste C, Saft C, Andrich J, Gold R, Falkenstein M. Response inhibition in Huntington's disease-a study using ERPs and sLORETA. Neuropsychologia. 2008;46(5):1290-7.

83. Fallgatter AJ, Ehlis AC, Seifert J, Strik WK, Scheuerpflug P, Zillessen KE, et al. Altered response control and anterior cingulate function in attention-deficit/hyperactivity disorder boys. Clin Neurophysiol. 2004;115(4):973-81.

84. Fallgatter AJ, Ehlis AC, Rosler M, Strik WK, Blocher D, Herrmann MJ. Diminished prefrontal brain function in adults with psychopathology in childhood related to attention deficit hyperactivity disorder. Psychiatry Res. 2005;138(2):157-69.

85. Bokura H, Yamaguchi S, Kobayashi S. Event-related potentials for response inhibition in Parkinson's disease. Neuropsychologia. 2005;43(6):967-75.

86. Polich J, Kok A. Cognitive and biological determinants of P300: an integrative review. Biol Psychol. 1995;41(2):103-46.

87. Kok A. On the utility of $\mathrm{P} 3$ amplitude as a measure of processing capacity. Psychophysiology. 2001;38(3):557-77.

88. Overtoom CC, Verbaten MN, Kemner C, Kenemans JL, van Engeland H, Buitelaar JK, et al. Associations between eventrelated potentials and measures of attention and inhibition in the Continuous Performance Task in children with ADHD and normal controls. J Am Acad Child Adolesc Psychiatry. 1998;37(9):977_ 85.

89. Lawrence CA, Barry RJ, Clarke AR, Johnstone SJ, McCarthy R, Selikowitz M, et al. Methylphenidate effects in attention deficit/ hyperactivity disorder: electrodermal and ERP measures during a continuous performance task. Psychopharmacology (Berl). 2005;183(1):81-91.

90. Verbaten MN, Overtoom CC, Koelega HS, Swaab-Barneveld H, van der Gaag RJ, Buitelaar J, et al. Methylphenidate influences on both early and late ERP waves of ADHD children in a continuous performance test. J Abnorm Child Psychol. 1994;22(5):561-78.

91. Klorman R, Salzman LF, Pass HL, Borgstedt AD, Dainer KB. Effects of methylphenidate on hyperactive children's evoked responses during passive and active attention. Psychophysiology. 1979;16(1):23-9.

92. Brandeis D, van Leeuwen TH, Steger J, Imhof K, Steinhausen HC. Mapping brain functions of ADHD children. In: Hirata K, Koga Y, Nagata K, Yamazaki K, editors. Recent advances in human brain mapping. Amsterdam: Elsevier; 2002. p. 649-54.

93.• Neale BM, Medland SE, Ripke S, Asherson P, Franke B, Lesch $\mathrm{KP}$, et al. Meta-analysis of genome-wide association studies of attention-deficit/hyperactivity disorder. J Am Acad Child Adolesc Psychiatry. 2010;49(9):884-97. doi:10.1016/j.jaac.2010.06.008. A recent meta-analysis on GWAS in ADHD that revealed no genom-wide significance, but highlight the potential role of potential gene by gene and gene by environment interactions, as well as the potential impact of rare variants for $A D H D$.

94. Mick E, Todorov A, Smalley S, Hu X, Loo S, Todd RD, et al. Family-based genome-wide association scan of attention-deficit/ hyperactivity disorder. J Am Acad Child Adolesc Psychiatry. 2010;49(9):898-905 e3. doi:10.1016/j.jaac.2010.02.014.

95. Doyle AE, Willcutt EG, Seidman LJ, Biederman J, Chouinard VA, Silva J, et al. Attention-deficit/hyperactivity disorder endophenotypes. Biol Psychiatry. 2005;57(11):1324-35.

96. Albrecht B, Brandeis D, Uebel H, Valko L, Heinrich H, Drechsler $\mathrm{R}$, et al. Familiality of neural preparation and response control in childhood attention deficit-hyperactivity disorder. Psychol Med. 2013;43(9):1997-2011. doi:10.1017/S003329171200270X.

97. McLoughlin G, Asherson P, Albrecht B, Banaschewski T, Rothenberger A, Brandeis D, et al. Cognitive-electrophysiological indices of attentional and inhibitory processing in adults with ADHD: familial effects. Behav Brain Funct. 2011;7:26.

98. Dougherty DM, Bjork JM, Moeller FG, Harper RA, Marsh DM, Mathias CW, et al. Familial transmission of Continuous 
Performance Test behavior: attentional and impulsive response characteristics. J Gen Psychol. 2003;130(1):5-21. doi:10.1080/ 00221300309601271.

99. Gizer IR, Ficks C, Waldman ID. Candidate gene studies of ADHD: a meta-analytic review. Hum Genet. 2009;126(1):51-90.

100. Noain D, Avale ME, Wedemeyer C, Calvo D, Peper M, Rubinstein M. Identification of brain neurons expressing the dopamine D4 receptor gene using BAC transgenic mice. Eur J Neurosci. 2006;24(9):2429-38.

101. Asghari V, Sanyal S, Buchwaldt S, Paterson A, Jovanovic V, Van Tol HH. Modulation of intracellular cyclic AMP levels by different human dopamine D4 receptor variants. J Neurochem. 1995;65(3):1157-65.

102. Asghari V, Schoots O, van Kats S, Ohara K, Jovanovic V, Guan $\mathrm{HC}$, et al. Dopamine D4 receptor repeat: analysis of different native and mutant forms of the human and rat genes. Mol Pharmacol. 1994;46(2):364-73.

103. Faraone SV, Mick E. Molecular genetics of attention deficit hyperactivity disorder. Psychiatr Clin N Am. 2010;33(1):159-80.

104. Li D, Sham PC, Owen MJ, He L. Meta-analysis shows significant association between dopamine system genes and attention deficit hyperactivity disorder (ADHD). Hum Mol Genet. 2006;15(14): 2276-84. doi:10.1093/hmg/ddl152.

105. Munafo MR, Yalcin B, Willis-Owen SA, Flint J. Association of the dopamine D4 receptor (DRD4) gene and approach-related personality traits: meta-analysis and new data. Biol Psychiatry. 2008;63(2):197-206.

106. Manor I, Tyano S, Mel E, Eisenberg J, Bachner-Melman R, Kotler $\mathrm{M}$, et al. Family-based and association studies of monoamine oxidase A and attention deficit hyperactivity disorder (ADHD): preferential transmission of the long promoter-region repeat and its association with impaired performance on a continuous performance test (TOVA). Mol Psychiatry. 2002;7(6):626-32. doi:10. 1038/sj.mp.4001037.

107. Manor I, Tyano S, Eisenberg J, Bachner-Melman R, Kotler M, Ebstein RP. The short DRD4 repeats confer risk to attention deficit hyperactivity disorder in a family-based design and impair performance on a continuous performance test (TOVA). Mol Psychiatry. 2002;7(7):790-4. doi:10.1038/sj.mp.4001078.

108. Langley K, Marshall L, van den Bree M, Thomas H, Owen M, O'Donovan M, et al. Association of the dopamine D4 receptor gene 7-repeat allele with neuropsychological test performance of children with ADHD. Am J Psychiatry. 2004;161(1):133-8.

109. Kieling C, Roman T, Doyle AE, Hutz MH, Rohde LA. Association between DRD4 gene and performance of children with ADHD in a test of sustained attention. Biol Psychiatry. 2006;60(10):1163-5. doi:10.1016/j.biopsych.2006.04.027.
110. Gizer IR, Waldman ID. Double dissociation between lab measures of inattention and impulsivity and the dopamine transporter gene (DAT1) and dopamine D4 receptor gene (DRD4). J Abnorm Psychol. 2012;121(4):1011-23.

111. Albrecht B, Brandeis D, von Sandersleben HU, Valko L, Heinrich $\mathrm{H}, \mathrm{Xu} \mathrm{X}$, et al. Genetics of preparation and response control in ADHD: the role of DRD4 and DAT1. J Child Psychol Psychiatry Allied Discip. 2014;55(8):914-23. doi:10.1111/jcpp.12212.

112. Ciliax BJ, Drash GW, Staley JK, Haber S, Mobley CJ, Miller GW, et al. Immunocytochemical localization of the dopamine transporter in human brain. J Comp Neurol. 1999;409(1):38-56.

113. Spencer T, Biederman J, Wilens T. Pharmacotherapy of attention deficit hyperactivity disorder. Child Adolesc Psychiatr Clin N Am. 2000;9(1):77-97.

114. Shumay E, Fowler JS, Volkow ND. Genomic features of the human dopamine transporter gene and its potential epigenetic States: implications for phenotypic diversity. PLoS One. 2010;5(6):e11067.

115. Franke B, Vasquez AA, Johansson S, Hoogman M, Romanos J, Boreatti-Hummer A, et al. Multicenter analysis of the SLC6A3/ DAT1 VNTR haplotype in persistent ADHD suggests differential involvement of the gene in childhood and persistent ADHD. Neuropsychopharmacology. 2010;35(3):656-64.

116. Loo SK, Specter E, Smolen A, Hopfer C, Teale PD, Reite ML. Functional effects of the DAT1 polymorphism on EEG measures in ADHD. J Am Acad Child Adolesc Psychiatry. 2003;42(8):98693. doi:10.1097/01.CHI.0000046890.27264.88.

117. Cornish KM, Manly T, Savage R, Swanson J, Morisano D, Butler $\mathrm{N}$, et al. Association of the dopamine transporter (DAT1) 10/10repeat genotype with ADHD symptoms and response inhibition in a general population sample. Mol Psychiatry. 2005;10(7):686-98.

118. Kim JW, Kim BN, Cho SC. The dopamine transporter gene and the impulsivity phenotype in attention deficit hyperactivity disorder: a case-control association study in a Korean sample. J Psychiatr Res. 2006;40(8):730-7. doi:10.1016/j.jpsychires.2005. 11.002 .

119. Caldu X, Vendrell P, Bartres-Faz D, Clemente I, Bargallo N, Jurado MA, et al. Impact of the COMT Val108/158 Met and DAT genotypes on prefrontal function in healthy subjects. Neuroimage. 2007;37(4):1437-44. doi:10.1016/j.neuroimage. 2007.06.021.

120. Dresler T, Ehlis AC, Heinzel S, Renner TJ, Reif A, Baehne CG, et al. Dopamine transporter (SLC6A3) genotype impacts neurophysiological correlates of cognitive response control in an adult sample of patients with ADHD. Neuropsychopharmacology. 2010;35(11):2193-202. 